\title{
Lingual hamartoma in a patient with morphea
}

\author{
Thales Pereira de Azevedo ${ }^{1}$, Cecilia Xavier Lagalhard Victer ${ }^{2}$, Adriana Ferreira ${ }^{3}$, Danielle Carvalho Quintella ${ }^{4}$ Tullia Cuzzi ${ }^{5}$ and Marcia \\ Ramos-e-Silva ${ }^{6 *}$ \\ ${ }^{1}$ Dermatologist and former Post-Graduation Student - Sector of Dermatology and Post Graduation Course - University Hospital and School of Medicine, Federal \\ University of Rio de Janeiro, Brazil \\ ${ }^{2}$ Dermatologist - Sector of Dermatology and Post-Graduation Course in Dermatology - University Hospital and School of Medicine - Federal University of Rio \\ de Janeiro, Brazil \\ ${ }^{3}$ Dentist and Facial-Buco-Maxillo Surgeon - Sector of Dermatology and Post Graduation Course - University Hospital and School of Medicine, Federal University \\ of Rio de Janeiro, Brazil \\ ${ }^{4}$ Assistant Professor, Department of Pathology - University Hospital and School of Medicine, Federal University of Rio de Janeiro, Brazil \\ ${ }^{5}$ Associate Professor - Department of Pathology - University Hospital and School of Medicine, Federal University of Rio de Janeiro, Brazil \\ ${ }^{6}$ Professor and Chair - Sector of Dermatology and Post-Graduation Course in Dermatology - University Hospital and School of Medicine - Federal University of \\ Rio de Janeiro, Brazil
}

\begin{abstract}
Background: Hamartomas are excessive growth of mature cells and tissues usually present in the affected organ with architectural derangement. Lingual hamartomas are uncommon.

Methods: A 49-year-old woman presented a mass on the body of the tongue to the left, with mild dysphagia and dyslalia. She has lesions of localized scleroderma in the limbs for the past 36 years. The diagnosis of hamartoma was based on the histopathological study.

Results: Despite the large size of the lesion and the minor impairment it caused a conservative management and only regular consultations were proposed due also to the fact the surgical approach could produce greater morbidity.

Conclusions: The authors discuss the epidemiologic data and differential diagnosis of lingual hamartoma, as well as the related literature. To date, no cases of lingual hamartomas in patients with scleroderma have been reported.
\end{abstract}

\section{Introduction}

Many tumor-like lesions such as hamartomas, pyogenic granulomas and hemangiomas can affect the tongue and they need to be differentiated from cancers [1].

Hamartomas, first reported by Alberecht in 1904, are described as benign malformations constituted by disorganized mature tissues that usually occur in the affected site, but with predominance of a specific tissue. They are more frequent in the liver, spleen, kidney, lung, skin and pancreas $[2,3]$.

Lingual hamartoma is a very rare condition and was first described by Stamm and Tauber, in 1945 [4]. It can be solitary or appear in association with syndromes, such as oral-facial-digital syndrome (OFDS), which is a genetic syndrome with ten subtypes that comprises oral, facial and digital malformations [3].

\section{Case report}

A 49-year-old woman presented at our Sector of Dermatology complaining of progressive volume increase on the left side of her tongue for the last 6 years, with mild dysphagia and dyslalia. She had been diagnosed 36 years before with localized scleroderma in the left arm and leg, but the disease was stable for more than 30 years. At clinical examination, there was poorly defined lesion that occupied the anterior $2 / 3$ of the left side of the anterior tongue, which was soft to palpation and with (Figure 1) with a pleated aspect of the mucosa. There was no deviation of the side of the tongue.

An electroneuromyography was performed and showed no abnormalities. A magnetic resonance imaging demonstrated a hyperintense mass at the left side of the tongue on T2-weighted images and did not demonstrate evidence of expansive lesions in the hypoglossal and trigeminal nerves. Due to the size of the lesion an incisional biopsy was performed. Histopathological examination demonstrated a large amount of adipose tissue, besides blood vessels, nerve filaments, connective tissue and a few striated muscle fibers, characterizing abnormal proportion and distribution of those tissues elements (Figures 2 and 3).

*Correspondence to: Marcia Ramos-e-Silva, Rua Dona Mariana 143 / C-32, 22280-020 - Rio de Janeiro - Brazil, E-mail: ramos.e.silva@dermato.med.br

Key words: hamartoma, lingual, localized scleroderma, morphea, oral tumor, tongue

Received: April 02, 2018; Accepted: April 16, 2018; Published: April 19, 2018 

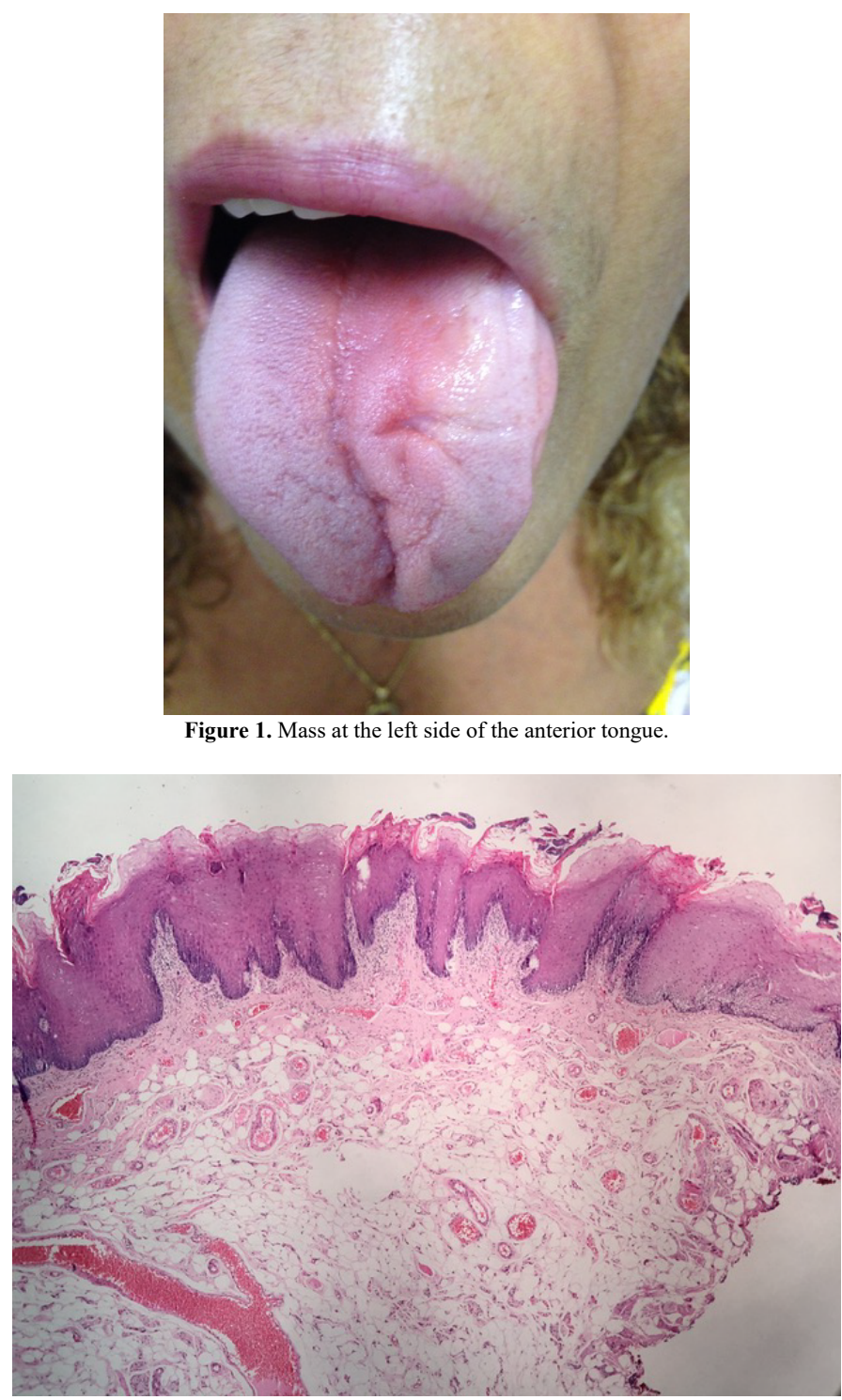

Figure 2. Connective tissue, adipose tissue and small vessels beneath the epithelium of the tongue. (HE, 40X)

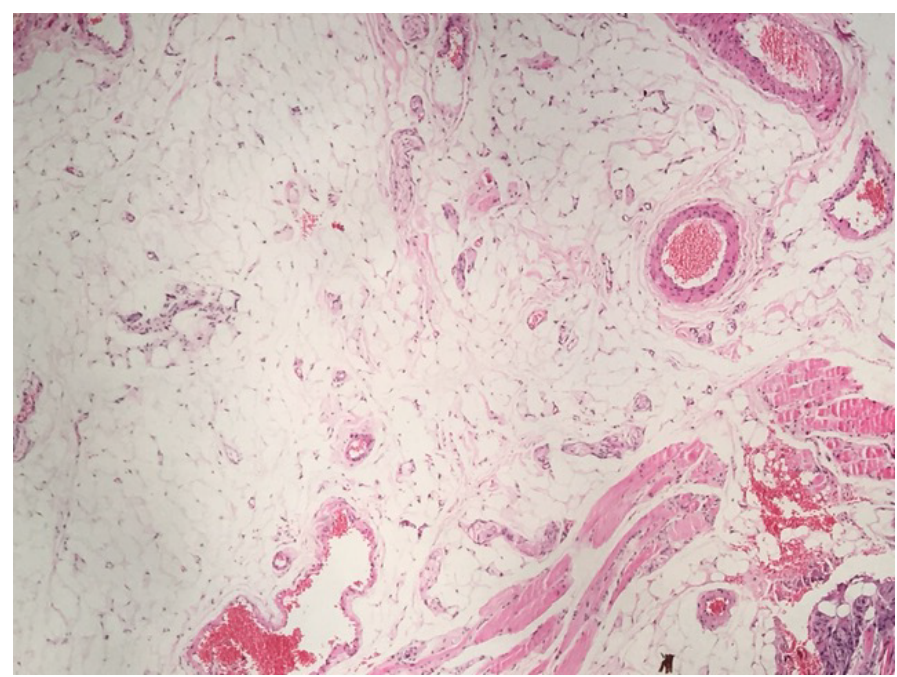

Figure 3. Muscle tissue observed focally. (HE, 100X)

\section{Discussion}

Hamartoma is a benign tumor of excessive growth in which there is presence of normal tissue components of the affected organ, arranged in a disordered way. The vast majority of lingual hamartomas reported were among the pediatric population [3-8] with only a few in the adults, mainly in women [1,9-12].

Most hamartomas of the tongue are asymptomatic, with some presenting dysphagia or globus sensation. The patient's symptom depends on the location and size of the lesion. Difficulties in feeding are the major reason for referral of pediatric patients [1,3-8].

A review performed by Takimoto et al. showed that the majority of lingual hamartomas were observed in the midline at the base of the tongue [6], while another review by Kreiger et al. mentioned the dorsal anterior tongue as the most affected area $[1,5]$.

Lingual hamartomas can occur as isolated lesions or associated with syndromes such as oral-facial-digital syndrome [13], tuberous sclerosis [14] and incomplete cleft palate [15].

Hamartomas can be pathologically subclassified according to the relative predominance of a specific endogenous tissue, so they may described as muscular, vascular, adipose tissue, and intramuscular capillary variants $[1,5]$. The hamartoma presented in this case was classified authors as an adipose tissue predominant type.

In our case, we chose a conservative management because of the few symptoms presented by the patient despite the large size of the lesion, and also because the surgical approach could lead to greater morbidity than the lesion itself. Most hamartomas reported in the literature have been of smaller size and have therefore been removed transorally, either by surgery [4] or by lasers [6]. Vashishth et al. suggest that large hamartoma involving the tongue base and the vallecula can be safely removed using a suprahyoid pharyngotomy approach [1].

Finally, our patient had lesions of morphea diagnosed 36 years ago and, in a PubMed search, the authors could not find any previous reports of the association of lingual hamartoma with localized scleroderma in the same patient and for this reason we believe that this case is the first report of this association, although there did not seem to be a relation between these two diseases.

\section{Conclusion}

Lingual hamartoma is a rare cause of a tongue mass, especially in adults. The present report is a special case of lingual hamartoma in a patient with localized scleroderma.

\section{Conflict of interest}

The authors have no conflict of interest and there was no financial support.

\section{References}

1. Vashishth A, Mathur NN, Choudhary SR, Khanna G (2014) Giant vascular hamartoma of the tongue. Malays J Med Sci 21: 74-77. [Crossref]

2. Alberecht H. (1904) Uber hamartome. Dtsch Patho Ges 7: 153.

3. Wang HL, Chiang FY, Tai CF, Tsai KB, Wang LF. (2013) Lingual leiomyomatous hamartoma with bifid tip and ankyloglossia in a patient without oral-facial-digital syndrome: a case report and literature review. World J Surg Oncol 11: 230. [Crossref]

4. Stamm C, Tauber R. (1945) Hamartoma of the tongue. Laryngoscope 55: 140-146.

5. Kreiger PA, Ernst LM, Elden LM, Kazahaya K, Alawi F, et al. (2007) Hamartomatous tongue lesions in children. Am J Surg Pathol 31: 1186-1190. [Crossref] 
6. Takimoto T, Yoshizaki T, Umeda R (1989) Hamartoma of the tongue. Int J Pediatr Otorhinolaryngol 18: 157-161. [Crossref]

7. Takato T, Fukuda O, Ohhara Y, Yanai A, Hirabayashi S, et al. (1985) Hamartoma of the tongue: two case reports. Plast Reconstr Surg 5: 258-262.

8. Nakanishi K, Nomura J, Matsumura Y, Yanase S, Kato H, et al. (2012) Leiomyomatous hamartoma of the tongue in an infant: a case report. $J$ Dent Child (Chic) 79: 111-114. [Crossref]

9. Allon I, Allon DM, Hirshberg A, Shlomi B, Lifschitz-Mercer B, et al. (2012) Oral neurovascular hamartoma: a lesion searching for a name. J Oral Pathol Med 41: 348-353.

10. PERRI FA (1956) Myoepithelial hamartoma of tongue. AMA Arch Otolaryngol 64: 289-290. [Crossref]
11. Gillett D, Fahmy F, Eveson JW, Shotton JC (2003) Intramuscular capillary hamartoma of the tongue. J Laryngol Otol 117: 734-735. [Crossref]

12. de Faria PR, Batista JD, Duriguetto AF Jr, Souza KC, Candelori I, et al. (2008) Giant leiomyomatous hamartoma of the tongue. J Oral Maxillofac Surg 66: 1476-1480. [Crossref]

13. Doege TC, Thuline HC, Priest JH, Norby DE, Bryant JS (1964) Studies of a family with the oral-facial-digital syndrome. $N$ Engl J Med 271: 1073-1078. [Crossref]

14. Wallace H, Davis A, Spedding A (2001) Tongue-base hamartoma in tuberous sclerosis. $J$ Laryngol Otol 115: 149-150. [Crossref]

15. Ishii T, Takemori S, Suzuki JI (1968) Hamartoma of the tongue. Report of a case. Arch Otolaryngol 88: 171-173. [Crossref]

Copyright: (C2018 Pereira de Azevedo T. This is an open-access article distributed under the terms of the Creative Commons Attribution License, which permits unrestricted use, distribution, and reproduction in any medium, provided the original author and source are credited. 